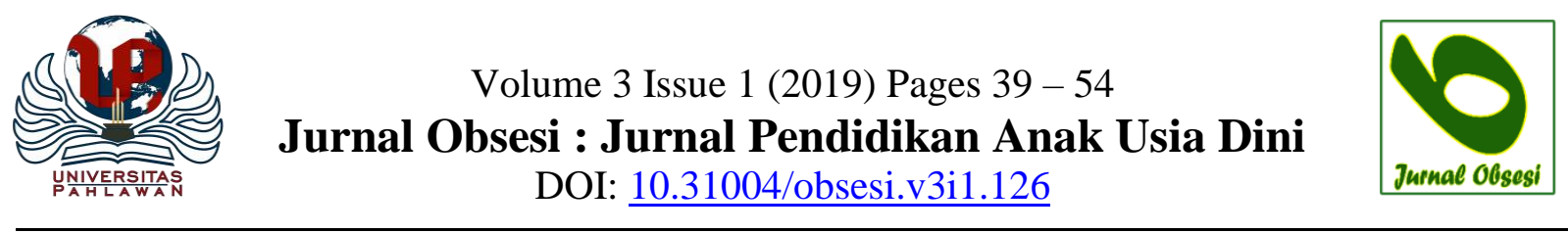

\title{
Pendidikan Karakter Anak Usia Dini melalui Sastra Klasik Fabel Versi Daring
}

\author{
Juanda $^{\square}$ \\ Program Studi Bahasa dan Sastra Indonesia, Fakultas Bahasa dan Sastra, \\ Universitas Negeri Makassar
}

\begin{abstract}
The purpose of this study is to find value in fables in online media in Indonesia. This research is a qualitative descriptive study. The source of the data comes from the web http://repositori.kemdikbud.go.id. collection of South Sulawesi fables. Data collection techniques use non-interactive techniques by conducting intensive readings on fables and recording actively using the fill method. Data validity to test the validity of this study using data triangulation and triangulation methods. Data analysis techniques use an interactive analysis model. Data analysis was performed using Miles and Huberman (1994) models, namely: (1) doing fable as research objects, (2) doing data reduction, (3) presenting data, (4) interpreting data obtained according to theory, and (5) produce conclusions. There are fourteen character education found: caring, respect, cooperation, helper, democracy, filial piety, humility, creativity, forgiveness, courage, discipline, hard work, honesty, and religion. Fable character education can be applied to the formation of early children's character with early child care and early childhood with children, namely: 1 . Look at the child as a person; 2 . Participation in empathy with children; 3 . The interpretive attitude respects children the expressions and meanings of world life; 4. Guiding children in sensitive ways 5. Early care and education is a dialogical process between child and caregiver/teacher.
\end{abstract}

Keywords: Fables, Character, Early Childhood

\begin{abstract}
Abstrak
Tujuan penelitian ini adalah mengeksplorasi nilai-nilai karakter dalam fabel media daring di Indonesia. Penelitian ini merupakan penelitian deskriptif kualitatif. Sumber data berasal dari web http://repositori.kemdikbud.go.id. kumpulan fabel Sulawesi Selatan. Teknik pengumpulan data menggunakan teknik noninteraktif dengan melakukan pembacaan intensif pada fabel dan melakukan pencatatan secara aktif dengan metode analisis isi. Validitas data untuk menguji validitas penelitian ini menggunakan teknik triangulasi data dan triangulasi metode. Teknik analisis data menggunakan model analisis interaktif. Analisis data dilakukan dengan mengikuti model Miles dan Huberman (1994), yaitu: (1) melakukan identifikasi fable sebagai objek penelitian, (2) melakukan reduksi data, (3) menyajikan data, (4) menginterpretasikan data yang diperoleh sesuai teori, dan (5) menyusun simpulan. Pendidikan karakter yang ditemukan ada empat belas yaitu: peduli, hormat, kerja sama, penolong, demokrasi, berbakti, rendah hati, kreatif, pemaaf, pemberani, disiplin, kerja keras, jujur, dan religius. Pendidikan karakter dalam fabel dapat diterapkan pada pembentukan karakter anak usia dini dengan pengasuhan anak usia dini (sejak bayi) dan pendidikan dini anak-anak dengan cara yang sejalan dengan orientasi perspektif anak, yaitu:1.Melihat anak itu sebagai pribadi; 2.Keikutsertaan yang empati dengan anak; 3.Sikap interpretatif menghormati anak ungkapan-ungkapan dan arti kehidupan dunia; 4.Membimbing anak dengan cara yang sensitif 5.Perawatan dini dan pendidikan adalah proses dialogis antara anak dan pengasuh/guru.
\end{abstract}

Keywords: Fabel, Karakter, Anak Usia Dini

@ Jurnal Obsesi Prodi PG-PAUD FIP UPTT 2019

$\triangle$ Corresponding author :

Address : Jl. Borong Raya, Delta Mas I Makassar

Email : juanda@unm.ac.id

ISSN 2356-1327 (Media Cetak)

ISSN 2549-8959 (Media Online) 


\section{PENDAHULUAN}

Pembentukan karakter harus dimulai sejak usia dini. Ada berbagai media yang digunakan dalam membentuk karakter antara lain sastra. Sastra sebagai paradigma menciptakan kembali rasa kehidupan (Suryaman, 2010: 114). Kondisi kehidupan masyarakat dewasa ini sangat memprihatikan, perkelahian, pembunuhan, kesenjangan sosial, ketidakadilan, perampokan, begal, korupsi, dan lain-lain (Marta, 2014). Sastra memiliki peran yang penting dalam perkembangan moral, sosial, dan psikologi (Wahyu, 2011: 176), menjadikan sastra khususnya fabel sangat relevan dalam pendidikan karakter anak (Wulandari, 2015: 67; Waryanti, 2015). Karya sastra yang baik berangkat dari kesadaran bahwa manusia adalah sosok yang kompleks yang dapat direduksi secara sederhana menjadi alegori moral (Budiman, 2012: 133). Oleh karena itu, bentuk sastra yang paling tepat digunakan dalam pembentukan karakter anak usia dini adalah sastra klasik jenis fabel yang dapat diakses secara daring. Penelitian mengenai karakter dalam fabel telah dilakukan oleh para ahli. Namun, kajian mereka tidak mengeksplorasi lebih jauh mengenai nilai edukasi khususnya pada fabel media daring. Pemilihan cerpen media daring jaman millenial, era 4.0. yang memprioritaskan digital dalam semua disiplin ilmu. Jadi, semua cerpen dalam penelitian ini dapat diakses secara daring atau online sehingga guru dan orang tua dapat dengan mudah mengaksesnya. Peneliti memfokuskan permasalahan penelitian ini pada nilai edukasi karakter yang terkandung dalam fabel media daring. Tujuan penelitian ini adalah mengeksplorasi nilai-nilai karakter dalam fabel media daring di Indonesia.

Penelitian karakter dalam sastra yang dikaitkan dengan pendidikan anak usia dini telah dilakukan oleh pakar antara lain; D’Anna, C. A., \& Balsink Krieg, D, (2005) penelitian ini menguji model apresiasi dan pemahaman fabel pada anak TK. Hasil penelitian menunjukkan elemen cerita berkaitan dengan kualitas moral yang dihasilkan. Selanjutnya Khimji \& Maunder, R. E. (2012) meneliti isi cerita anak-anak yang dapat memberikan wawasan budaya. Hasil penelitian menyarankan memasukkan kegiatan mendongeng ke kelas awal tahun sehingga memungkinkan pendidik mengembangkan pemahaman budaya siswa dan memberikan kepada peneliti sumber daya metodologis yang berharga dengan mempelajari perspektif sosiokultural. Irawati dan Neli Purwani (2013) meneliti pembentukan karakter melalui sastra anak terjemahan.

Hasil penelitian menunjukkan perlunya stimulasi pada anak-anak dengan memanfaatkan sastra anak mutlak diperlukan dalam setiap pendidikan pada jenjang usia. Penekanan bahasa pada anak telah diteliti Spencer, Petersen, D. B., Slocum, T. A., \& Allen, M. M. (2014) tentang kemampuan pemahaman cerita anak prasekolah dan kaitannya dengan penguasaan bahasa. Sebuah desain penelitian kelompok quasi-eksperimental, pretest/post test diambil dari anak-anak prasekolah.

Perbedaan yang signifikan secara statistik antara kelompok perlakuan dan pembanding ditemukan pada retell dan langkah-langkah pemahaman cerita. Hasil penelitian ini merekomendasikan pendekatan penilaian dinamis secara budaya dan linguistik pada anak-anak diidentifikasi dengan intervensi secara intensif. Yono (2014) meneliti keragaman fabel yang terdapat pada suku Sentani dapat dijadikan sebagai sarana membangun karakter anak. Dari hasil analisis diketahui bahwa terdapat beberapa karakter universal yang dapat diambil dari fabel Sentani, di antaranya cinta terhadap Tuhan dan cinta 
makhluk ciptaan-Nya, kerja keras, kejujuran, dan rendah hati. Stkip, N., Tuanku, P., Riau, T., Studi, P., Anak, P., \& Dini, U. (2015) meneliti pantang larang, sastra lisan masyarakat Melayu Kampar. Ungkapan pantang larang memiliki relevansi pada pendidikan karakter; Surya (2017) menggunakan model pembelajaran pendidikan karakter pada abad ke-21 pada anak usia dini merupakan proses pemberdayaan potensi peserta didik proses humanisasi (humanizing), dan proses pembudayaan, model-model pembelajaran pendidikan yaitu model pembelajaran penanaman nilai berbasis perkembangan penalaran moral, analisis nilai dan project citizen, efektif digunakan membantu peserta didik mengembangkan kompetensi menjadi warga negara yang baik.

Penelitian yang mengeksplorasi cerita dan merahasiakan sesuatu kepada anak-anak selama era Holocaust. Diteliti Gildersleeve \& Batorowicz, B.(2017) di Roberto Benigni Hidup itu indah 'Life is Beautiful' (1997) dan Mark Herman The Boy in the Striped Piyama (2008) orang tua berusaha menyembunyikan informasi perang kepada anak-anak, guna mencegah kecemasan. Di kontraskan dengan dokumen sejarah Dongeng dari Auschwitz tidak menyangkal kenyataan hidup yang mengerikan di kamp, tetapi menggunakan genre dongeng peri sebagai jaminan moralitas dan kelangsungan hidup. Cremin, Flewitt, R., Swann, J., Faulkner, D., \& Kucirkova, N. (2017) meneliti Pendekatan Vivian Gussin Paley untuk bercerita dan berakting. Dalam kasus ini diteliti anak usia 3 hingga 5 tahun. Hasil penelitian ini menunjukkan narasi anak dikonstruksi bersama selama interaksi antara orang dewasa dan anak dan teman sebaya model lisan, sebagaimana cerita mereka ditulis oleh orang dewasa kemudian didramatisasi oleh teman-teman mereka. Kajian ini berkontribusi secara signifikan terhadap pengetahuan tentang bagaimana narasi anak-anak muda dikonstruksi bersama melalui beberapa mode di kelas.

Penelitian (Betawi, 2018:1) memberikan wawasan integritas moral anak-anak di sekolah Indonesia di Amman, Yordania. Penelitian ini mengukur efektivitas program pendidikan karakter yang diimplementasikan di satu sekolah swasta pada anak-anak. Pengukuran peningkatan integritas moral pada anak-anak dalam empat dimensi yang berbeda (empati, kejujuran, rasa hormat, dan keberanian). Hasilnya menunjukkan signifikansi skala integritas moral yang tidak meningkat dalam uji post mendukung kelompok eksperimen. Terakhir penelitian (Hodges, T. S., McTigue, E., Wright, K. L., Franks, A. D., \& Matthews, S. D., 2018) penulis membingkai penelitian dalam teori membaca, tanggapan pembaca dan teori pengkodean ganda, serta teori perkembangan instruksi dengan mendesain ulang peta cerita, untuk mempertahankan manfaat instruksi struktur teks, juga memfasilitasi siswa mencapai tingkat pemahaman berdasarkan karakter yang lebih dalam. Dibingkai dalam teori tanggapan pembaca, teori pengkodean ganda, dan teori perkembangan pengambilan perspektif, anak-anak meningkatkan pengetahuan tentang teks sambil mengambil perspektif karakter yang ada di dalamnya.

Fabel merupakan cerita kehidupan hewan yang berperilaku manusia. Fabel ini dapat dijadikan sarana membentuk karakter anak dari segi kepribadian, mengasah emosi dan imajinasi. Karena ketertarikan anak kepada binatang tinggi, dongeng mengambil binatang sebagai tokohnya. Melalui cerita fabel kepada anak orang tua gampang menanamkan nilai kepribadian. Mengajarkan kepada anak 
perilaku tidak sombong, rendah hati. Kerendahan hati menurut pakar Davis et al., (2011) dan karya Pirical, Davis et al., (2013) dalam (Van Tongeren, 2014:63) merupakan kebajikan yang ditandai downregulation of egois-motif sebagai pendukung orientasi lainnya, serta pandangan akurat tentang diri sendiri yang dapat diungkapkan dengan berbagai cara (misalnya, pujian, peningkatan kesadaran diri tentang sifat-sifat negatif (Van Tongeren, Green, J. D., Hulsey, T. L., Legare, C. H., Bromley, D. G., \& Houtman, A. M., 2014).

Fabel selain ditujukan kepada anakanak, juga kepada orang dewasa. Karakter yang diperankan oleh binatang, tumbuhan, atau benda mati tersebut dapat dianalogikan dengan karakter manusia yang sesungguhnya (Yono, 2014: 103). Menurut Yono (2014: 105-105) Dalam sastra klasik ada unsur budaya, sejarah, bahkan unsur ideologi di samping aspek emosional, intelektual, sosial, dan moralitas. Adaptasi Cassell and McNeill's (1991:382-385) dalam (Lwin, 2017: 38-39). Tipologi, gerakan pendongeng diklasifikasikan antara lain ke dalam Isyarat mimik: gerakan tangan, lengan atau tubuh seperti pidato (misalnya saat memberlakukan atau meniru tindakan karakter tokoh. "Para pendongeng dari tradisi ini ada nilai kesenangan, kesombongan. dan prasangka manusia biasa. Kesenangan dalam hal-hal yang tak terbatas dan abadi. Cerita rakyat dan mitologi Celtic, Irlandia memiliki tradisi merayakan kehidupan pada masa-masa lampau (Dibattista, 2007).

Sejarah Asal usul Genre Fabel diidentikkan dengan Aesop, seorang tokoh dari zaman Yunani klasik. Dia pertama menyebutkan kisah moral Aesopian dibuat oleh Aristophanes, Plato, dan Aristoteles dalam 5-4 abad S.M. Namun, penulis hanya merujuk pada kisah-kisah ini sebagai bentuk-bentuk retoris persuasif, dan tidak ada koleksi yang bertahan atau analisis kontemporer dari genre tersebut. Bukti sugesti bahwa Aesop menciptakan banyak cerita yang berisi nilai moral, dan diteruskan dalam tradisi lisan selama beberapa abad sebelum ditulis oleh Demetrius dari Phalerum sekitar 300 S.M. Jacobs (1970) dalam Jose, P. E., D’Anna, C. A., \& Balsink Krieg, D. (2005). Terjemahan selanjutnya fabel dari Aesopian dibuat oleh orang Yunani dan Romawi, kemudian Perancis, Jerman, dan Penulis Inggris. Jadi, saat ini ada banyak variasi dongeng telah dicetak, dan tidak otentik.

Apa fabel itu? Contoh, "The Tortoise and the Hare", "Kura-kura dan Kelinci' dongeng ini dianggap sebagai genre khas karena sering dicetak ulang. Tetapi mengapa dianggap prototipikal? Perry, 1959 dalam (Jose, D’Anna, C. A., \& Balsink Krieg, D., 2005). mendefinisikan fabel sebagai "Sebuah dongeng berhubungan suatu peristiwa fiktif di masa lalu untuk tujuan yang jelas serta menggambarkan suatu kebenaran; dan "pencerita sebuah dongeng, fabel, prihatin sebelum semuanya dengan makna metaforis dari ceritanya". Karakteristik fabel adalah (a) panjang pendeknya, (b) fitur berbicara binatang sebagai metafora manusia, dan (c) melibatkan tindakan signifikan secara moral yang terstruktur dalam narasi untuk pembentukan moral. Fabel "Kura-kura dan Kelinci", kelinci terlalu percaya diri, tukang tidur, dan kehilangan ras pada kura-kura yang terusmenerus lamban. Narasi ini tampaknya akan menanamkan pesan moral dalam domain tindakan manusia, ketekunan akan dihargai tetapi bukan kemalasan dan terlalu percaya diri. Fabel ini membatasi genre ke narasi sederhana. Keringkasannya memungkinkan mengingat dan menceritakan kisah-kisah dalam tradisi 
lisan tempat fabel diciptakan. Selain itu, keringkasan ini dianggap sesuai dengan anak-anak (Jose, D’Anna, C. A., \& Balsink Krieg, D., 2005).

Banyak definisi karakter yang bersifat kompleksitas. Wynne dan Walberg (1984) karakter didefinisikan sebagai perilaku atau kata-kata yang relevan secara moral. Definisi lainnya menggambarkan karakter sebagai seperangkat nilai moral di dalam pikiran, kasih sayang, dan perilaku seseorang secara konsisten (Licokona,1999). Selain itu, karakter sering mengacu pada pendekatan umum individu terhadap tanggung jawab kehidupan sosial yang didukung oleh perolehan keterampilan pro-sosial, pengetahuan reaksi emosional pro-sosial terhadap kesulitan orang lain (Hay, Nash, \& Pedersen, 1981) seperti kehidupan pinggiran kota telah menciptakan homogenisasi di lingkungan binaan, gaya hidup, sikap, dan nilai-nilai dari penduduk mereka. Pinggiran kota mewujudkan kekuatan ekonomi, politik, dan budaya yang besar di Amerika Utara (Onusko, 2015) subjek-subjek yang terpinggirkan, fenomena ekonomi (Lee, 2018). Berkowitz (1997) membuat perbedaan antara moral, kualitas karakter dan yang bukan. Kualitas moral tidak secara khusus bermoral, tetapi mendukung tindakan moral (misal keberanian, kreativitas, dan ketekunan). Jadi, karakter merupakan tingkah laku seseorang (Ainusyamsi dan Fadlil, 2010: $31)$.

Sastra menyajikan model kehidupan dengan tokoh-tokoh berkarakter yang pantas diteladani (Nurgiyantoro, 2010:36). Pembentukan karakter bangsa diupayakan melalui pendidikan nilai yang diperoleh melalui lingkungan, keluarga, teman, dan media massa yang dapat dilaksanakan sejak usia dini (Wening, 2012: 64). Sastra klasik merupakan sarana penemuan jati diri bangsa (Kosasih, 2013: 227). Sastra merupakan inspirasi yang dapat dibentuk variannya (alur, karakter tokoh, dan setting) menurut (Hutchison, 2013: 45). Menurut Wyne kata karakter bersumber dari bahasa Yunani "Charassian" to mark. Karakter artinya sifat-sifat kejiwaan, ahlak atau budi pekerti (Anwar, 2013: 4). Pendidikan karakter dalam hubungannya dengan sesama berupa karakter peduli, santun, dan demokratis (Harsono, 2014). Pendidikan karakter dapat diintegrasikan dalam empat keterampilan berbahasa, yaitu: menyimak, berbicara, membaca, dan menulis (Maryasa, Iqbal Hilal, dan Eka sofya Agustina, 2014:5).

Karakter adalah cara berpikir dan berperilaku setiap individu untuk hidup dan bekerja sama dalam lingkup, keluarga, masyarakat, bangsa, dan Negara (Setiawati, 2015: 66). Kesusatraan menanamkan kebenaran tentang kehidupan seperti tanggung jawab dalam kehidupan yang berkaitan dengan moral (Brower, 2015:65). Ruang lingkup orang terletak pada kekuatannya mempengaruhi orangorang di sekitarnya, ruang lingkup tanggung jawab (Bracken, 2018:7).

Rekonseptualisasi masa kecil selalu muncul perbedaan aspek afektif (Sherbine, 2015: 785). Selanjutnya pendidikan karakter merupakan suatu proses membina budi pekerti peserta didik (Setiawati, 2015: 68). Karakter adalah sebuah akumulasi kebiasaan yang dilakukan hingga orang itu memiliki kesadaran diri (Waryanti, 2015: 163). Menurut Ernawati (2017: 120) pendidikan karakter adalah pendidikan yang bertujuan memberikan tuntunan kepada peserta didik untuk mengembangkan nilai-nilai dan karakter yang telah tertanam pada dirinya masingmasing secara sadar baik di sekolah ataupun di lingkungan sekitar.

Secara keseluruhan, definisi ini menyarankan pembentukan karakter di masa kecil bergantung pada 
pengembangan dasar sosial emosional dan

kemampuan kognitif, termasuk kemampuan membedakan antara benar dan salah, kemampuan membedakan perspektif orang lain, akuisisi sosial, manifesta-perilaku prososial, dan kemampuan memiliki dan menggunakan pengetahuan yang berharga untuk rasa sejahtera. Namun, masih belum jelas apakah proses ini berkembang selama masa kanak-kanak untuk membentuk struktur (Shoshani, 2018). Karakter dipadankan dengan akhlak, kebiasaan, perangai, dan tabiat (Widyawanti dan Ida, 2018: 3).

Pusat Kurikulum Kementerian Pendidikan Nasional (2011: 10) telah merumuskan pendidikan karakter yang mencakup aspek-aspek sebagai berikut: (1) religius; (2) jujur, (3) Toleran, (4) disiplin, (5) kerja keras, (6) kreatif, (7) mandiri, (8) demokratis, (9) rasa ingn tahu, (10) semangat kebangsaan, (11) cintah tanah air, (12) menghargai prestasi, (13) bersahabat atau komunikatif, (14) cinta damai, (15) gemar membaca, (16) peduli lingkungan, (17) Peduli Sosial, (18) tanggung Jawab.

Enam karakter ditekankan dalam Program Anak Usia Dini Kurikulum prasekolah nasional, yaitu "Nuri Kurikulum" adalah kurikulum umum untuk anak-anak usia 3 hingga 5 tahun di Korea Selatan dilaksanakan pada 2012 untuk anak usia 5 tahun, kemudian diperluas ke anak-anak usia 3 dan 4 pada tahun 2013. "Nuri Kurikulum" memastikan kualitas diberbagai pengaturan dan mempromosikan kontinuitas antara pendidikan anak usia dini dan sekolah dasar (Organisasi bidang Kerjasama dan Pengembangan Ekonomi, 2012). Ini menekankan pendidikan karakter yang mempertegas bahwa sikap dasar, kebiasaan, dan sifat-sifat karakter terbentuk pada anak usia dini memiliki efek seumur hidup dan pendidikan prasekolah memiliki pengembangan efek yang kuat pada bidang-bidang ini (Lee, 2013). Pada tahun 2009, the Ministry of Education, Science, and Technology (MEST) membuat kebijakan baru tentang perlunya pendidikan karakter pada anak usia dini (Yang, Lee, MEST, 2012).

Penekanan enam karakter utama pada awal program masa kecil, sebagai berikut: 1.Peduli anak, peduli terhadap hak dan martabatnya sendiri, orang lain, semua makhluk hidup, dan lingkunganberhubungan erat dengan eksistensi manusia. Anak-anak belajar bahwa orang harus melindungi lingkungan alam untuk memastikan keharmonisan koeksistensi manusia dan alam, dan mereka belajar kepedulian dan perhatian untuk teman, keluarga, tetangga, hewan, dan tumbuhan. 2.Menghormati anak-anak, mempertimbangkan tata cara menghormati diri sendiri dan orang lain serta menghargai hubungan dengan orang tua, saudara, tetangga, dan semua orang secara individual di dunia. Mereka belajar tidak sendirian; mereka tinggal bersama dengan orang lain dalam suatu Komunitas internasional. Anak-anak melihat, mendengar, merasakan, dan mengerti bahwa orang berbeda, dan belajar saling menerima dan kerja sama. Mereka belajar rasa hormat mengenai budaya dan tradisi sendiri, orang lain, dan kehidupan lingkungan sekitarnya.

3. Kerja sama, kerja sama adalah kesediaan berkontribusi pada kelompok yang bekerja bersama secara berurutan untuk mencapai tujuan dan tugas bersama. Kerja sama termasuk berbagi pendapat, informasi, dan sumber daya; membentuk ikatan; dan mengakui tanggung jawab pribadi dan usaha kelompok. Anak belajar bagaimana mempertahankan hubungan interpersonal yang positif dan interdependensi, pribadi tanggung jawab, 
dan bekerja sama dengan orang lain dalam kelompok. 4.Berbagi, berbagi tidak hanya menggunakan material juga berarti terus menerus-bekerja untuk kebutuhan orang lain dari hati yang baik tanpa harapan menerima sesuatu kembali. Anak-anak belajar memahami artinya berbagi dan berpartisipasi dalamberbagai kegiatan. 5.Memesan -Order adalah nilai inti demokrasi dan kebajikan yang harus ditanamkan pada anak di oder to live sebagai warga negara yang demokratis. Anak-anak belajar bagaimana mematuhi perintah dan mengikuti aturan hukum. 6. Berbakti, kesopanan, kesalehan. Berbakti adalah konsep dasar cinta dan hormat kepada orang tua dan leluhur. Ini adalah salah satu yang paling mendasar dan kebajikan-kebajikan penting yang ingin orang tua kembangkan pada anak-anak mereka (Lee, 2013).

\section{METODOLOGI}

Metode yang dipergunakan dalam penelitian ini adalah metode deskriptif kualitatif. Data yang digunakan berupa deskripsi kata-kata dan frasa kualitatif. Nilai karakter dideskripsikan berdasarkan kutipan yang ada dalam fabel. Penelitian ini menggunakan pendekatan objektif. Sumber data berasal dari URL: http://www.dongenganakindonesia1.com/2 014/06/cerita-si-kancil-kerbau-danbuaya.html; $\quad$ http://ceritadongengindonesia.blogspot.com/2015/08/kisahdongeng-bangau-dan-

kera.html; http://kumbercer.blogspot.com/2 016/02/cerita-rusa-dan-kura-kura.html; dan

http://repositori.kemdikbud.go.id/3096/1/K umpulan\%20Cerita\%20Fabel\%20Sulawesi \%20Selatan.pdf. Teknik pengumpulan data menggunakan teknik noninteraktif dengan melakukan pembacaan intensif pada fabel dan melakukan pencatatan secara aktif dengan metode analisis isi. Validitas data untuk menguji validitas penelitian ini menggunakan teknik triangulasi data dan triangulasi metode. Teknik analisis data menggunakan model analisis interaktif. Analisis data dilakukan dengan mengikuti model Miles dan Huberman (1994), yaitu: (1) melakukan identifikasi cerpen sebagai objek penelitian, (2) melakukan reduksi data, (3) menyajikan data, menginterpretasikan data yang diperoleh sesuai teori, dan (5) menyusun simpulan.

\section{HASIL DAN PEMBAHASAN Hasil Penelitian}

Pendidikan karakter karakter yang ditemukan dalam kelima fable ini beragam. Judul fable tersebut adalah Kuda dengan Lintah, Burung Gagak dengan Siput, Si Kera dan Burung Bangau, Rusa dengan Kura-kura, dan Buaya dengan Kerbau.

Fable Kuda dengan Lintah (FKL). Menceritakan seekor kuda dan lintah yang sedang mencari makan. Bilamana mereka saling bertemu lintah di ejek oleh si kuda sehingga lintah mengajukan tantangan kepada di kuda yaitu mengadakan perlombaan lari. Tantangan itu membuat si kuda tersinggung dan menerima tantangan tersebut. Akhirnya mereka mengadakan perlombaan lari. Lintah menyerahkan abaaba kepada si kuda. Setelah memberi abaaba berlarilah si kuda dengan sekuat tenaga kemudian lintah langsung melekatkan diri pada kaki si kuda. Ketika sampai di garis finis si lintah langsung melepaskan diri dari kaki si kuda dan menjadi pemenang dalam perlombaan lari tersebut dengan mengatakan telah lama ia menunggu si kuda di garis finis. Si kuda tidak percaya dengan kekalahannya kemudian mengadakan perlombaan ulang, tetapi si lintah tetap menjadi pemenang, kuda merasa malu karena telah mengejak si lintah. Akhirnya karena terlalu capek dan lapar si kuda mati. 
Fabel Burung Gagak dengan Siput (FBGS). Menceritakan seekor burung gagak mengajak siput melakukan perlombaan lari. Awalnya siput menolak namun gagak mengejek dan mencela siput. Siput tersinggung dan sakit hati lalu menerima tantangan gagak. Pada hari perlombaan akhirnya siput menang dan gagak memohon kepada siput membersihkan badannya. Saat siput mengeluarkan badannya dari rumah siput, ia dimakan oleh gagak.

Fabel Si Kera dan Burung Bangau (FKB). Menceritakan keadaan di sebuah hutan seekor burung bangau dan kera yang bersahabat. Mereka bekerja sama membuat kebun. Sambil menjaga kebun yang telah mereka buat. Si bangau mencarikan kutu si kera. Setelah itu bergantian si kera yang mencarikan kutu si bangau namun si bangau tidak sengaja mencabut bulu bulu dari si bangau sampai ia tidak dapat terbang mencari makan. Setelah bulunya tumbuh kembali dan ia bisa terbang, ia pun dapat mencari ikan besar di tengah laut dan danau. Si kera yang menyaksikannya. Ia meminta diajari cara menangkap ikan besar. Namun, ia di tipu oleh si bangau bahwa jika ada ikan yang menghempaskan dirinya ke pinggir sungai segeralah memeluknya padahal itu adalah ombak besar tanpa ikan yang kemudian menenggelamkannya.

Fabel Rusa dengan Kura-kura (FRK). Menceritakan seekor rusa sedang berjalan mencari makanan di tengah padang. Di tengah perjalanan ia bertemu seekor kura-kura yang juga sedang mencari makanan dan berjalan sangat lambat. Melihat pergerakan kura-kura yang berjalan lambat, rusa dengan sombongnya mencelanya. Rusa kemudian mengajak kura-kura beradu lomba lari. Keesokan harinya mereka bertemu di tempat yang telah disetujui melaksanakan lomba lari. Di tengah perlombaan rusa yang mengira akan memenangkan perlombaan justru heran melihat kura-kura dapat mengalahkannya. Setelah peristiwa tersebut, rusa sadar bahwa ia tidak boleh menyombongkan diri dan meremehkan keahlian siapapun.

Fabel Buaya dengan Kerbau (FBK). Menceritakan kampung yang dilanda banjir dahsyat dan seekor buaya hanyut. Setelah banjir surut buaya menyadari sebatang kayu menimpa pangkal ekornya. Tiba-tiba seekor kerbau muncul di sungai. Buaya meminta tolong kepada kerbau. Buaya mengatakan bahwa jika dia bersedia menolongnya dia berjanji tidak akan memakan kerbau lagi dan itu berlaku pada keturunannya. Alangkah terkejutnya kerbau ternyata buaya ingkar janji dan berniat memakannya. Kerbau langsung berunding kepada buaya bahwa sebelum dia dimakan harus ada keterangan dari tiga orang (sesuatu) yang hanyut ditempat itu. Setelah masing-masing menyampaikan pendapatnya dua orang yaitu tikar tua dan nyiru tua berpendapat sama yaitu setelah seseorang berbuat baik pasti akan dibalas dengan kejahatan. Namun berbeda dengan pelanduk yang justru malah mengelabui buaya dan berhasil menyelamatkan kerbau.

Kelima fable di atas memiliki berbagai jenis pedididkan kakter, yaitu: peduli, hormat, kerja sama, penolong, demokrasi, berbakti, rendah hati, kreatif, pemaaf, pemberani, disiplin, kerja keras, jujur, dan religius. Secara lengkap dapat dilihat dalam table 1.1. di bawah ini.

\section{Tabel 1.1 Pendidikan Karakter Fabel}

\begin{tabular}{|l|l|l|l|}
\hline No & \multicolumn{1}{|c|}{ Judul } & \multicolumn{1}{|c|}{$\begin{array}{c}\text { Sing } \\
\text { katan }\end{array}$} & \multicolumn{1}{|c|}{ Karakter } \\
\hline 1. & $\begin{array}{l}\text { Kuda } \\
\text { dengan } \\
\text { Lintah }\end{array}$ & FKL & $\begin{array}{l}\text { Sopan, kreatif, } \\
\text { pemaaf, } \\
\text { pemberani }\end{array}$ \\
\hline 2. & $\begin{array}{l}\text { Burung } \\
\text { Gagak } \\
\text { dengan } \\
\text { Siput }\end{array}$ & FBGS & $\begin{array}{l}\text { Kerja sama, } \\
\text { kreatif, } \\
\text { pemberani, } \\
\text { disiplin }\end{array}$ \\
\hline 3. & $\begin{array}{l}\text { Si Kera } \\
\text { dan } \\
\text { Burung } \\
\text { Bangau }\end{array}$ & FKB & $\begin{array}{l}\text { Kerja kama, } \\
\text { demokrasi, kerja } \\
\text { keras }\end{array}$ \\
\hline
\end{tabular}




\begin{tabular}{|l|l|l|l|}
\hline No & \multicolumn{1}{|c|}{ Judul } & $\begin{array}{c}\text { Sing } \\
\text { katan }\end{array}$ & \multicolumn{1}{|c|}{ Karakter } \\
\hline 4. & $\begin{array}{l}\text { Rusa } \\
\text { dengan } \\
\text { Kura-Kura }\end{array}$ & FRK & $\begin{array}{l}\text { Hormat, } \\
\text { demokrasi, } \\
\text { kreatif, pemaaf, } \\
\text { pemberani, kerja } \\
\text { keras, jujur, } \\
\text { religious }\end{array}$ \\
\hline 5. & $\begin{array}{l}\text { Buaya } \\
\text { dengan } \\
\text { Kerbau }\end{array}$ & FBK & $\begin{array}{l}\text { Peduli, penolong, } \\
\text { demokrasi, kerja } \\
\text { kreatif, } \\
\text { keras, religus }\end{array}$ \\
\hline
\end{tabular}

Selanjutnya uraian secara lengkap dapat dilihat di bawah ini.

\section{Peduli}

Peduli terhadap hak dan martabatnya sendiri, orang lain, semua makhluk hidup, dan lingkungan berhubungan erat dengan eksistensi manusia. Anak-anak belajar bahwa orang harus melindungi lingkungan alam untuk memastikan keharmonisan ekosistensi manusia dan alam, dan mereka belajar kepedulian dan perhatian untuk teman, keluarga, tetangga, hewan, dan tumbuhan. Fabel Kerbau dan Buaya memperlihatkan tokoh Pelanduk yang peduli kepada Kerbau yang teraniaya. Kutipan dapat dilihat pada data (1) di bawah ini.

(1). "Pelanduk peduli pada kerbau yang dimangsa buaya dengan berteriak agar kerbau melompat setelah sampai di air dangkal sehingga terhindar dari tipuan buaya." (FBK).

\section{Menghormati}

Hormat mempertimbangkan tata cara menghormati diri sendiri dan orang lain serta menghargai hubungan dengan orang tua, saudara, tetangga, dan semua orang secara individual di dunia. Mereka belajar tidak sendirian; mereka tinggal bersama dengan orang lain dalam suatu komunitas internasional. Anak-anak melihat, mendengar, merasakan, dan mengerti bahwa orang berbeda, dan belajar saling menerima dan kerja sama. Mereka belajar rasa hormat mengenai budaya dan tradisi sendiri, orang lain, dan kehidupan lingkungan sekitarnya. Rasa hormat sebagai sikap saling meghormati satu sama lain, hormat kepada yang lebih tua, menyayangi yang muda. Pada kalangan masyarakat Indonesia dua hal tersebut sudah langka terjadi karena tidak ada kesadaran di dalam diri masing-masing. Data (2) memperlihatkan tokoh Rusa yang menghormati kura-kura karena telah memperoleh kemenangan.

(2) Menghormati kura-kura atas prestasi, "rusa mengakui kemenangan kura-kura yang telah mengalahkannya dalam perlombaan lari." (FRK)

\section{Kerja Sama}

Kerja sama adalah kesediaan berkontribusi pada kelompok yang bekerja bersama secara berurutan untuk mencapai tujuan dan tugas bersama. Kerja sama termasuk berbagi pendapat, informasi, dan sumber daya; membentuk ikatan; dan mengakui tanggung jawab pribadi dan usaha kelompok. Anak belajar bagaimana mempertahankan hubungan interpersonal yang positif dan interdependensi, pribadi tanggung jawab, dan bekerja sama dengan orang lain dalam kelompok ditunjukkan pada kutipan.

(3). "Siput bekerja sama dengan temantemannya untuk mempersiapkan perlombaan" (FBGS).

(4). "Untuk perintang waktu, sambil menjaga kebun mereka memutuskan untuk saling mencari kutu" (FKB)

\section{Berbagi, Penolong}

Berbagi tidak hanya menggunakan material juga berarti terus menerus bekerja untuk kebutuhan orang lain dari hati yang baik tanpa harapan menerima sesuatu kembali. Anak-anak belajar memahami artinya berbagi dan berpartisipasi dalam berbagai kegiatan. 
(5) "Buaya hanyut di sungai dan tertindih kayu sehingga susah untuk bergerak, maka kerbau menolong dengan menaikkan keatas pinggang dan membawanya kesungai." (FBK).

\section{Demokrasi}

Demokrasi adalah nilai inti demokrasi dan kebajikan yang harus ditanamkan pada anak dioder to live sebagai warga negara yang demokratis. Anak-anak belajar bagaimana mematuhi perintah dan mengikuti aturan hukum. Menyelesaikan sesuatu berdasarkan kesepakatan. (6) "Sambil berbincang akhirnya mereka sepakat untuk membuat kebun bersama" (FKB).

(7)."Sesudah keduanya mufakat lalu terbanglah burung bangau itu melayangmelayang di atas permukaan laut" (FKB).

(8). “Akhirnya kura-kura dan rusa sepakat untuk melakukan lomba lari." (FRK).

(9).“'Sebelum kerbau dimangsa buaya, mereka sepakat mendengarkan dahulu pendapat tiga orang (Pelanduk, tikar, dan nyiru) yang hanyut di sungai itu tentang adakah suatu perbuatan yang baik dibalas dengan kejahatan?”. (FBK).

\section{Berbakti,}

Berbakti, kesopanan, kesalehan. Berbakti adalah konsep dasar cinta dan hormat kepada orang tua dan leluhur. Berkata baik merupakan sikap berbicara yang penuh dengan kesopanan dan mampu menempatkan bahasa yang pantas sesuai dengan situasi dan kondisi kepada siapa kita bicara. Rendah hati ini adalah salah satu yang paling mendasar dan kebajikankebajikan penting yang ingin orang tua kembangkan pada anak-anak mereka (Lee, 2013).Tokoh lintah menunjukkan kesopanan dalam berbicara kepada kuda, seperti dalam data (10) di bawah ini.
(10) "Secara sopan lintah menyerahkan kepada si kuda untuk memberi aba-aba" (FKL)

\section{Kreatif}

Kreatif merupakan daya cipta, mempunai kmampuan untuk mampu menciptakan yang baru. Kereatif merupakan usaha yang dilakuakan oleh para tokoh agar lepas dari kesulitan atau berhasil meraih sesustu seperti juara dalam lomba lari. Data (11), (12), (13), dan (14) menunjukkan secara jelas usaha kereatif yang dilakukan oleh lintah, siput, kurakura, dan pelanduk.

(11) "Lintah menempelkan dirinya kepada si kuda yang telah berlari dan melepaskan diri di garis finis dan menjadi pemenang" (FKL)

(12) "Liput berusaha untuk selalu mencari jalan keluar agar menang dari gagak" (FBGS)

(13) Kura-kura mencari cara agar dia menang dalam perlombaan lari dengan rusa. Dan akhirnya menang (FRK)

(14) "Pelanduk berusaha melepaskan kerbau dari cengkraman buaya dengan berpura-pura tuli agar kerbau pergi ke pinggir sugai sehingga buaya tak dapat lagi mengikuti kerbau". (FBK).

\section{Pemaaf}

Pemaaf merupakan unsur pengakuan kekeliruan, keteledoran, kesalahan yang telah dilakukan seseorang kepada sesamanya tanpa adanya rasa benci dan dendam. Salah satu wujudnya yaitu meminta maaf. Kutipan dapat dilihat dalam data (15) dan (16) di bawah ini.

(15) "Kuda mengakui kesalahan dan menyesal telah mengejek si lintah dan meminta maaf kepada si lintah" (FKL)

(16) "Akhirnya rusa memutuskan berdamai dan minta maaf kepada kura-kura dan tidak lagi memandang rendah si kura-kura." (FRK). 


\section{Pemberani}

Pemberani, merupakan sifat pantang menyerah. Seseorang yang pantang menyerah. Seseorang pernah mengalam kegagalan dia selalau mencari cara agar terhindar dari kegagalan tersebut untuk kedua kalinya.

(17). "Si lintah mengajukan tantangan untuk berlomba lari karena telah di ejek oleh si kuda" (FKL)

(18). Burung gagak mengajak siput untuk melakukan perlombaan lari. Awalnya siput menolak namun gagak kemudian mengejek dan mencela siput. Siput tersinggung dan sakit hati lalu menerima tantangan gagak. (FBGS).

(19). Keesokan harinya mereka bertemu di tempat yang telah disetujui untuk melaksanakan lomba lari.(FRK)

\section{Disiplin}

Disiplin merupakan perasaan taat dan patuh terhadap nilai-nilai yang dipercaya merupakan tanggung jawabnya. Disiplin merupakan kebiasaan pelaksanakan sesuatu sesuai dengan waktu yang telah ditentukan, seperti dalam data (20) di bawah ini.

(20) Yaitu ditunjukkan pada kutipan "Keduanyadatang tepat waktu dihari perlombaan yang telah disepakati. (FBGS)

\section{Kerja keras}

Kerja keras merupakan sebuah perbuatan yang mulia. Seseorang yang melaksanakan sesuatusecara sungguhsungguh untuk bisa mendapatkan apa yang dia inginkan seperti yang diperlihatkan dalam tokoh kera, burung bngau dan rusa dalam data (21), (22), dan (23) di bawah ini.

(21)"Pada hari yang ditentukan mereka pergi menebas rumput di lereng gunung untuk dijadikan kebun lalu ditanami jagung" (FKB)
(22)."Pagi hari di sebuah padang seekor kura-kura sedang mencari makanan dengan menyusuri hutan belantara." (FRK).

(23). "Setelah burung bangau tidak dapat terbang lagi.Setiap pagi ia hanya mencari belalang di pinggir sawah dekat lereng gunung itu. Ia hanya melompat-lompat mengejar belalang karena tidak dapat terbang". (FBK)

\section{Jujur}

Jujur merupakan perilaku yang mencerminkan adanya kesesuaian anatar hati, perkataan, dan perbuatan. Jujur merupakan salah satu sifat manusia yang sulit diterapkan. Sifat jujur biasanya diterapkan oleh orang-orang yang sudah terlatih sejak kecil. Tokoh kura-kura jujur kepada rusa bahwa dia lamban berjalan, data (24) di bawah ini.

(24). Kura-kura mengakui kekurangannya yaitu sangat lambat dalam berjalan dan merasa tidak mampu mengalahkan rusa." (FRK).

\section{Religius}

Religius adalah sikap dan perilaku yang patuh dalam melaksanakan ajaran agama yang dianutnya. Tokoh Kura-kura menyerahkan sepenuhnya kepada Tuhan apa yang akan terjadi. Begitu pula tokoh Kerbau, seperti dalam data (25) dan (26) di bawah ini.

(25) Kita belum tahu apa yang akan kejadian nanti, bagaimana kehendak Tuhan. Mungkin saya tidak dapat berlari karena terlalu banyak makan (FRK) (26). "Kerbau berdoa di dalam hatinya, meminta perlindungan dari tuhan yang maha adil agar ia dapat terhindar dari buaya." (FBK). 


\section{PEMBAHASAN}

Fabel yang diangkat dari masyarakat Sulawesi Selatan pada penelitian ini menonjolkan karakter pemberani, kreatif dan kerja sama. Berbeda dengan penelitian (Yono, 2014) fabel Sentani, di antaranya cinta terhadap Tuhan dan cinta makhluk ciptaan-Nya, kerja keras, kejujuran, dan rendah hati. Penelitian ini menemukan berbagai karakter yang dapat digunakan untuk anak usia dini dalam peningkatan kualitas moral yang sejalan dengan peneltian Jose, D'Anna, C. A., \& Balsink Krieg, D, (2005) dan Brower (2015). Fable rusa dengan kura-kura dan Buaya dengan Kerbau memiliki unsur karakter religi. Religi merupakan salah satu unsur budaya yang harus ditanamkan sejak usia dini sesuai penelitian Khimji \& Maunder, R. E. (2012) isi cerita anak-anak yang dapat memberikan wawasan budaya. Surya (2017) menggunakan model pembelajaran pendidikan karakter pada abad ke-21 pada anak usia dini merupakan proses pemberdayaan potensi peserta didik proses humanisasi (humanizing), dan proses pembudayaan, model-model pembelajaran pendidikan yaitu model pembelajaran penanaman nilai berbasis perkembangan penalaran moral yang mendukung penelitian ini. Penelitian (Betawi, 2018) memberikan wawasan integritas moral anak-anak di sekolah.

Sastra anak dapat dimanfaatkan pada pendidikan setiap jenjang usia (Irawati dan Neli Purwani, 2013). Fable Kuda dengan Lintah memperlihatkan kesantunan tokoh lintah terhadap kuda. Hal ini membuktikan perlunya penekanan penggunaan bahasa yang sopan pada anak (Harsono, 2014). Penelitian ini mendukung penelitian Spencer, Petersen, D. B., Slocum, T. A., \& Allen, M. M. (2014) tentang kemampuan pemahaman cerita anak parasekolah dan kaitannya dengan penguasaan bahasa.
Ada berbagai tokoh yang pantas diteladani (Nurgiyantoro, 2010) dalam fable karena kecerdikannya seperti kancil. Tokoh yang memiliki kemampuan mempengaruhi orang di sekitarnya dan memiliki tanggung jawab (Bracken, 2018). Tokoh ini mengalami varian (Hutchison, 2013).

Hasil penelitian ini mengugkapkan adanya berbagai hal yang pantang dilakukan yaitu meninggalkan seseorang bilamana tidak dibutuhkan atau menolong orang karena ada maunya seperti dalam fable Buaya dengan Kerbau, orang menganyutkan nyiru dan tikar tua di sungai karena tidak digunakannya lagi. Hal ini sesuai penelitian Nurmarlina (2015) tentang ungkapan pantang larang memiliki relevansi pada pendidikan karakter. Penelitian yang mengeksplorasi cerita dan merahasiakan sesuatu kepada anak-anak dengan cara penyampaian sesuatu secara tidak langsung yaitu melalui perantaraan binatang sebagai alegori hal ini sesuai penelitian Gildersleeve \& Batorowicz, B.(2017) orang tua berusaha menyembunyikan informasi perang kepada anak-anak, guna mencegah kecemasan.

Anak usia dini perlu didongengkan melalui orang tua di rumah dan guru di sekolah. Hal ini mendukung penelitian (Hodges, T. S., McTigue, E., Wright, K. L., Franks, A. D., \& Matthews, S. D., 2018) perlunya pendalaman karakter melalui membaca, menulis, dan berbicara dan mendengarkan dan perlunya anak memiliki keterampilan berbahasa (Maryasa, Iqbal Hilal, dan Eka Sofyan Agustina, 2014). Pendidikan karakter dimulai di lingkungan keluarga (Wenning, 2012) untuk mempertahankan jati diri bangsa (Kosasih, 2013). Pedongeng perlu menyertainya dengan akting agar anak dengan mudah mentransfer nilai karakter dongeng tersebut sebagaimana dikemukakan Cremin, Flewitt, R., Swann, 
J., Faulkner, D., \& Kucirkova, N. (2017) yang menegaskan perlunya bercerita sambil berakting.

Ada empat belas (14) jenis karakter yang ditemukan dalam penelitian ini, yaitu peduli, hormat, kerja sama, penolong, demokrasi, berbakti, rendah hati, kreatif, pemaaf, pemberani, disiplin, kerja keras, jujur, dan religius. Penelitian ini memiliki nilai karakter yang kurang dibandingkan dengan Pusat Kurikulum Kementerian Pendidikan Nasional (2011) telah merumuskan delapan belas pendidikan karakter, yaitu: mandiri, rasa ingin tahu, semangat kebangsaan, cintah tanah air, dan gemar membaca. Selanjutnya bila dibandingkan dengan karaker dalam kurikulum Nuri di Korea Selatan dalam penelitian ini tidak ditemukan karakter berbagi, berbagi tidak hanya menggunakan material juga berarti terus menerus bekerja untuk kebutuhan orang lain dari hati yang baik tanpa harapan menerima sesuatu kembali. Anak-anak belajar memahami artinya berbagi dan berpartisipasi dalam berbagai kegiatan (Lee, 2013) padahal karakter ini dapat menjadikan anak lebih mandiri dan sukses terhindar dari problem sosial, pengemis.

Berdasarkan nilai karakter yang ditemulan dalam fabel maka perlu memperhatikan lima kriteria atau asumsi, mendekati pengasuhan anak usia dini (sejak bayi) dan pendidikan dini anak-anak dengan cara yang sejalan dengan orientasi perspektif anak yaitu:1.Melihat anak itu sebagai pribadi. Sebuah prasyarat untuk perspektif berorientasi anak bahwa anak dilihat sebagai seseorang dengan kebutuhan yang sama dengan manusia lainnya untuk dilihat, dihormati, termasuk, dicintai, dan di dipengaruhi oleh orang lain sebab rekonseptualisasi masa kecil selalu muncul perbedaan aspek afektif (Sherbine, 2015); 2.Keikutsertaan dan empati terhadap anak. 3.Sikap interpretatif menghormati anak, ungkapan-ungkapan dan arti kehidupan dunia. Ini melibatkan ucapan sebagai ekstensi yang berarti dari seorang anak cara memahami dan mengalami menjelajahi anak itu dunia dari artinya sebagai objek studi dalam dirinya sendiri, bukannya menguranginya dengan mengupasnya dengan cara-cara pemahaman orang dewasa. 5.Perawatan dini dan pendidikan adalah proses dialogis antara anak dan pengasuh/guru, keduanya berkontribusi pada tujuan pembelajaran dan terkadang guru dominan. Melalui sinyal ekspresif dan banding, seorang anak mengundang pengasuh untuk merespon dengan cara tertentu.

Demikian baik si anak maupun pengasuh bertanggung jawab bersama dalam pendidikan yang diterima anak (Sommer, Pramling Samuelsson, I., \& Hundeide, K., 2013). Pendidikan karakter merupakan suatu proses membina budi pekerti peserta didik (Setiawati, 2015).

Karakter sebagai akumulasi kebiasaan yang dilakukan hingga orang itu memiliki kesadaran diri (Waryanti, 2015). Ernawati (2017) menegaskan bahwa pendidikan karakter adalah pendidikan yang bertujuan memberikan tuntunan kepada peserta didik.

\section{KESIMPULAN}

Pendidikan karakter karakter yang ditemukan dalam kelima fabel ini beragam. Judul fabel tersebut adalah Kuda dengan Lintah, Burung Gagak dengan Siput, Si Kera dan Burung Bangau, Rusa dengan Kura-kura, dan Buaya dengan Kerbau. Pendidikan karakter yang ditemukan ada empat belas yaitu: peduli, hormat, kerja sama, penolong, demokrasi, berbakti, rendah hati, kreatif, pemaaf, pemberani, disiplin, kerja keras, jujur, dan religius.

Pendidikan karakter dalam fabel dapat diterapkan pada pembentukan 
karakter anak usia dini dengan pengasuhan anak usia dini (sejak bayi) dan pendidikan dini anak-anak dengan cara yang sejalan dengan orientasi perspektif anak, yaitu:1.Melihat anak itu sebagai pribadi; 2.Keikutsertaan yang empati dengan anak; 3.Sikap interpretatif menghormati anak ungkapan-ungkapan dan arti kehidupan dunia; 4.Membimbing anak dengan cara yang sensitif dengan menyesuaikan dan memperluas inisiatif mereka dan cara-cara pemahaman ke arah tujuan atau objek pendidikan, seperti mendukung dan mendorong minat dan keterlibatan emosional dan eksplorasi dalam tugas dan kegiatan yang penting untuk perkembangan mereka; dan 5.Perawatan dini dan pendidikan adalah proses dialogis antara anak dan pengasuh/guru, keduanya berkontribusi pada tujuan pembelajaran terkadang guru dominan.

\section{UCAPAN TERIMA KASIH}

Penulis mengucapkan terima kasih kepada reviewer, monev penelitian dan teman sejawat yang telah memberikan saran perbaikan artikel ini. Terkhusus kepada rekan yang membantu pengumpulan data.

\section{DAFTAR PUSTAKA}

Anwar, H. S. (2013). Membangun Karakter Bangsa.” Jurnal At'Ta'dibe. Jurnal Al'Ta'dib, 8(1), $1-17$.

Betawi, A. (2018). Calling for character education: Promoting moral integrity in early childhood education in jordan. Early Child Development and Care, 0(0), 1-12. https://doi.org/10.1080/03004430.2 018.1489383

Bower, C., Conan, A., Bernard, G., Archer, W., Bennett, A., Chesterton, G. K., ... Mase, J. (2015). Against Moral
Seriousness as a Literary Value: Casement, Conrad, and Leavis. https://doi.org/10.1093/camqtly/bfu 037

Budiman, M. (2012). Meninjau kembali hubungan antara sastra dan budi pekerti. Jurnal Pendidikan Karakter.

Cremin, T., Flewitt, R., Swann, J., Faulkner, D., \& Kucirkova, N. (2018). Storytelling and storyacting: Co-construction in action. Journal of Early Childhood Research, 16(1), 3-17. https://doi.org/10.1177/1476718X1 7750205

Dibattista, M. (2007). Yeats as a Writer of Fiction, 9(1), 45-58. https://doi.org/10.1093/litimag/imm 011

E, K. (2013). Sastra Klasik sebagai Wahana Efektif dalam Pengembangan Pendidikan Karakter. Jurnl Pendidikan Bahasa Dan Sastra Indonesia.

Endang, W. (2015). Pembelajaran Sastra Berbasis Karakter. Jurnal Bhasa Dan Sastra, 2(2), 157-164.

Ernawati. (2017). Menumbuhkan nilai Pendidikan Karakter Anak Melalui Dongeng Fabel dalam Pembelajaran. Pendidikan Dan Pembelajaran Dasar, 4, 120-133.

Gildersleeve, J., \& Batorowicz, B. (2018). 'He is telling us fairy tales': parental anxiety and wartime childhood in Life is Beautiful, The Boy in the Striped Pajamas and Fairy Tales from Auschwitz. Holocaust Studies, 24(1), 26-44. https://doi.org/10.1080/17504902.2 017.1340074

Hay, D. F., Nash, A., \& Pedersen, J. (1981). Responses of Six-MonthOlds to The Distress of Their Peers. Child Development, 52(3), 10711075.

Hodges, T. S., McTigue, E., Wright, K. L., Franks, A. D., \& Matthews, S. D. 
(2018). Transacting With Characters: Teaching Children Perspective Taking With Authentic Literature. Journal of Research in Childhood Education, 32(3), 343362.

Hutchison, H. (2013). Just Literary: Henry James and "the Law School Experiment." Literary Imagination, 15(1), $36-47$. https://doi.org/10.1093/litimag/imt0 25

Irawati, R. P. dan N. P. (2013). Nilai-Nilai Moralitas dan Budaya Asing Dalam Sastra Anak Terjemahan Melalui Pemaknaan Sastra Anak Oleh Anak. Lingua, 9(1), 46-53.

Jose, P. E., D’Anna, C. A., \& Balsink Krieg, D. (2005). Development of the Comprehension and Appreciation of Fables. Genetic, Social, and General Psychology Monographs, 131(1), 5-37.

Khimji, F., \& Maunder, R. E. (2012). Mediational Tools in Story Construction: An investigation of cultural influences on children's narratives. Journal of Early Childhood Research, 10(3), 294308.

Lee, G.-L. (2013). Re-emphasizing Character Education in Early Childhood Programs: Korean Children's Experiences. Childhood Education, 89(5), 315-322. https://doi.org/10.1080/00094056.2 013.830907

Lickona, T. (1999). Character Education: Seven Crucial Issues. Action in Teacher Education, 20(4), 77-84. https://doi.org/10.1080/01626620.1 999.10462937

Lwin, S. M. (2017). Narrativity and creativity in oral storytelling: Coconstructing a story with the audience. Language and Literature, 26(1), 34-53. https://doi.org/10.1177/0963947016 686602
Marta, R. A. (2014). Peran Sastrdalam Pembentukan Pendidikan Karakter Anak Bangsa. Wahana Didaktika.

Maryasa, Rizki, Iqbal Hilal, dan E. S. A. (2014). Pendidikan Karakter pada Pembelajaran Bahasa dan Sastra Indonesia di SMPN 1 Gunungsugih. Jurnal Kata, Bahasa, Sastra, Dan Pengajarannya, 1-12.

Nurgiyantoro, B. (2010). Sastra Anak dan Pembentukan Karakte. Jurnal Ilmiah Pendidikan, 29, 25-36.

One, S. T. (2005). No Title. European Early Childhood Education Research Journal, 13(2), 25-39.

Setiawati, L. (2015). Pembentukan Karakter siswa Melalui Pembelajaran Bahasa dan Sastra Indonesia. Jurnal Pendidikan, 16(1), 65-73.

Sherbine, K. (2016). Emerging childhoods and immanent becomings: considering difference in one child's encounters with popular culture. Discourse, 37(5), 785-797. https://doi.org/10.1080/01596306.2 015.1075732

Shoshani, A. (2018). Young Children's Character Strengths and Emotional Well-Being: Development of The Character Strengths Inventory for Early Childhood. The Journal of Positive Psychology, 1-17.

Sommer, D., Pramling Samuelsson, I., \& Hundeide, K. (2013). Early childhood care and education: A child perspective paradigm. European Early Childhood Education Research Journal, 21(4), 459-475.

https://doi.org/10.1080/1350293X.2 013.845436

Spencer, T. D., Petersen, D. B., Slocum, T. A., \& Allen, M. M. (2015). Large group narrative intervention in Head Start preschools: Implications for response to intervention. Journal of Early Childhood Research. 
54 | Pendidikan Karakter Anak Usia Dini melalui Sastra Klasik Fabel Versi Daring

https://doi.org/10.1177/1476718X1

3515419

Suryaman, M. (2018). Pendidikan karakter Melalui Pembelajaran Sastra.

Cakrawala Pendidikan, Jurnal Ilmiah Pendidikan, 29(edisi Khusus), 112-126.

Van Tongeren, D. R., Green, J. D., Hulsey, T. L., Legare, C. H., Bromley, D. G., \& Houtman, A. M. (2014). A Meaning-Based Approach to Humility: Relationship Affirmation Reduces Worldview Defense. Journal of Psychology and Theology, 42(1), 62-69.

Wahyu. (2011). Masalah dan Usaha Membangun Karakter Bangsa. Jurnal Komunitas, 3(1), 138-149.

Wenning, S. (2012). Pembentukan Karakter Bangsa Melalui Pendidikan Nilai. Jurnal Pendidikan Karakter, 2(1), 55-64.

Yenni Fitra Surya. (2017). Penggunaan Model Pembelajaran Pendidikan Karakter Abad 21\ pada Anak Usia Dini. Jurnal Obsesi, 1(2), 148-155.

Yono, S. (2014). Nilai Edukasi dalam Fabel Sentani. Jurnal Kandai, 10(1), 102-115. 